\title{
Percutaneous exclusion of post-transcatheter aortic valve replacement (TAVR) induced aortic pseudoaneurysm using an Amplatzer Vascular Plug 2 (AVP2)
}

Sunil P Singh, ${ }^{1}$ Harsh Agrawal, ${ }^{\oplus 1}$ Charles M Eichler, $^{2}$ Vaikom S Mahadevan ${ }^{\oplus 1}$

'Department of Internal Medicine, Division of Cardiovascular Medicine, UCSF, San Francisco, California, USA ${ }^{2}$ Department of Vascular Surgery, UCSF, San Francisco, California, USA

\section{Correspondence to}

Dr Harsh Agrawal,

harshagrawal@hotmail.com

Accepted 11 June 2019

A Check for updates

C) BMJ Publishing Group Limited 2019. No commercial re-use. See rights and permissions. Published by BMJ.

To cite: Singh SP, Agrawal $H$, Eichler CM, et al. BMJ Case Rep 2019:12:e228442. doi: $10.1136 /$ bcr-2018 228442

\section{DESCRIPTION}

Here we present a novel repair strategy of a rare aortic complication following transcatheter aortic valve repair (TAVR). A 73-year-old man with a history of mitral valve replacement secondary to endocarditis underwent a TAVR for severe aortic

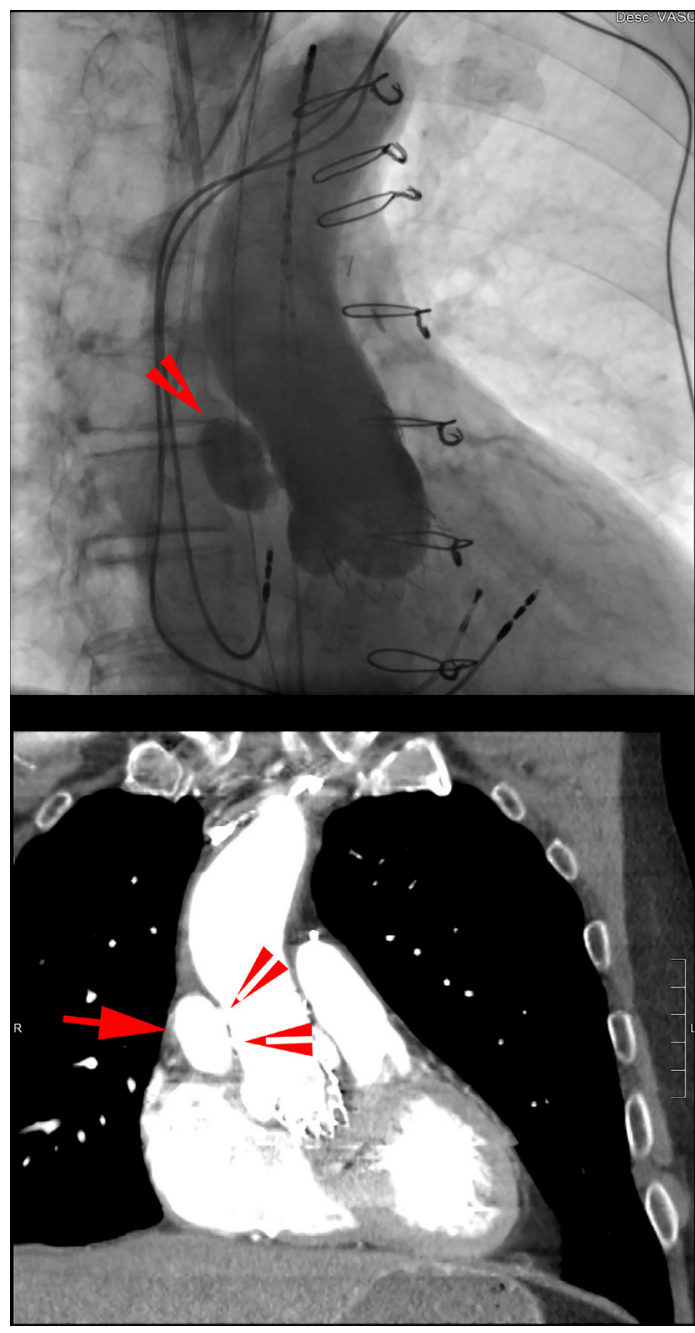

Figure 1 Top panel: pre-procedure aortography demonstrating pseudoaneurysm in communication with ascending aorta just distal to the transcatheter aortic valve repair scaffold (arrowhead). Bottom panel: pre-procedure CT scan demonstrating pseudoaneurysm (arrow) with two necks (arrowheads) communicating with ascending aorta.

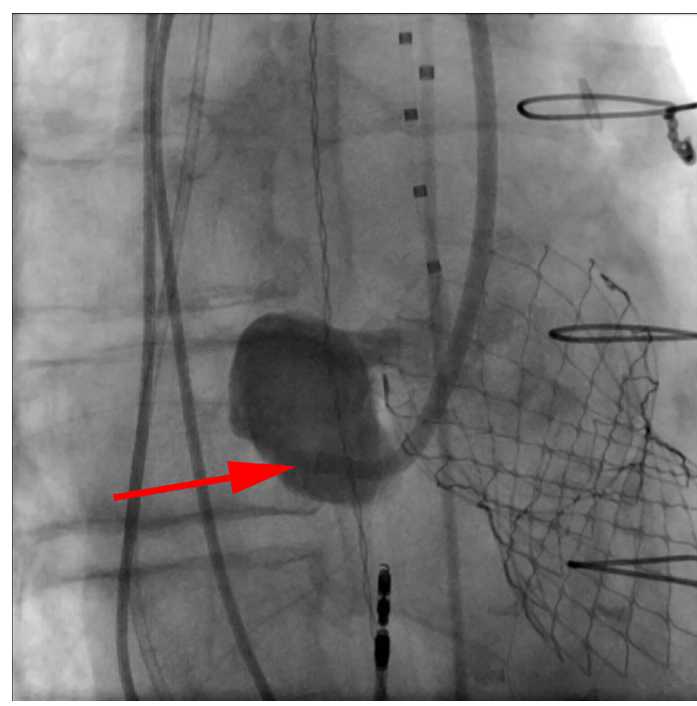

Figure 2 Initial engagement and opacification of pseudoaneurysm sac with a 6-French JR4 guide catheter (arrow).

insufficiency at an outside hospital (Medtronic Evolut R $34 \mathrm{~mm}$ Valve). After a routine follow-up, echocardiogram showing abnormal colour flow in the ascending aorta, a CT scan revealed TAVR leaflet thrombosis (requiring anticoagulation) and a $3.5 \times 3 \mathrm{~cm}$ pseudoaneurysmal sac with two communications into the ascending aorta just
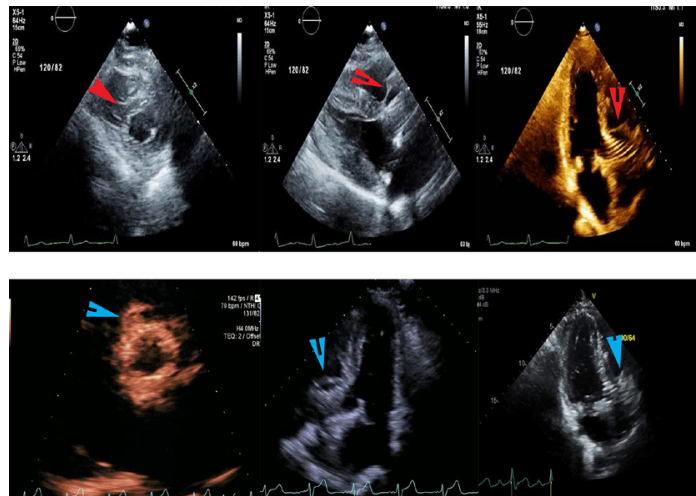

Figure 3 Top panel: aortography demonstrating Amplatzer Vascular Plug 2 (AVP2) device in place after release (arrowhead). Bottom panel: one-month postprocedure $\mathrm{CT}$ scan demonstrating AVP2 device in place with fully sealed pseudoaneurysm sac (arrow). 


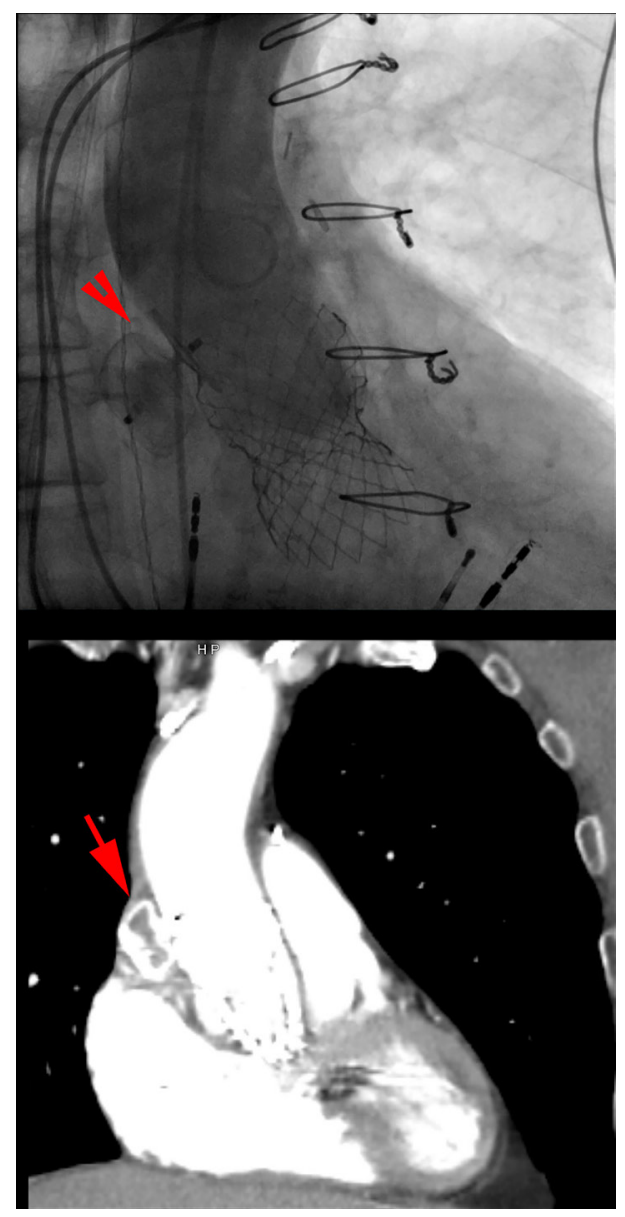

Figure 4 Top panel: pre-procedure echocardiogram in short axis, parasternal long axis and three-chamber view demonstrating the pseudoaneurysm sac. Bottom panel: post-procedure echocardiogram showing complete exclusion of the pseudoaneurysm sac. distal to the TAVR scaffold (figure 1: aortography-top, CT scan-bottom; figure 4: top-pre-procedure echo images with red arrow pointing towards the pseudoaneurysm).

Heart team evaluation of the case determined that thoracic endovascular aortic repair was not possible given the proximity of the pseudoaneurysm to the TAVR structure. A 6-French JR4 guide was used to engage the inferior neck of the pseudoaneurysm sac (figure 2) through the TAVR scaffold. An initial attempt at percutaneous coiling of the sac with a $20 \mathrm{~mm}$ Nestor vascular coil (Cook Medical, Bloomington, IN) failed to fill the cavity completely and was removed. Definitive repair of the sac was achieved using a $22 \mathrm{~mm}$ Amplatzer Vascular Plug 2 (St. Jude Medical, Saint Paul, MN). One month and 6 months post-procedure CT and echocardiogram showed a fully thrombosed and sealed off pseudoaneurysm sac with no residual communication with the ascending aorta (figure 3: aortography-top, CT scan-bottom; figure 4: bottom-post-procedure echo at 1 month with blue arrow pointing at the sealed PSA).

\section{Learning points}

- To our knowledge, this is the first reported case of transcatheter aortic valve repair-induced ascending aortic pseudoaneurysm.

- Our novel approach for percutaneous repair using an Amplatzer Vascular Plug 2 device appears to be both safe and efficacious.

Contributors SPS, HA, CME and VSM: planning, conduct, reporting, conception and design, acquisition of data or analysis and interpretation of data.

Funding The authors have not declared a specific grant for this research from any funding agency in the public, commercial or not-for-profit sectors.

Competing interests None declared.

Patient consent for publication Obtained

Provenance and peer review Not commissioned; externally peer reviewed.

Copyright 2019 BMJ Publishing Group. All rights reserved. For permission to reuse any of this content visit

https://www.bmj.com/company/products-services/rights-and-licensing/permissions/

BMJ Case Report Fellows may re-use this article for personal use and teaching without any further permission.

Become a Fellow of BMJ Case Reports today and you can:

- Submit as many cases as you like

- Enjoy fast sympathetic peer review and rapid publication of accepted articles

- Access all the published articles

- Re-use any of the published material for personal use and teaching without further permission

\section{Customer Service}

If you have any further queries about your subscription, please contact our customer services team on +44 (0) 2071111105 or via email at support@bmj.com.

Visit casereports.bmj.com for more articles like this and to become a Fellow 